\title{
Continuous-Infusion Vancomycin in Neonates: Assessment of a Dosing Regimen and Therapeutic Proposal
}

\author{
Manon Tauzin ${ }^{1 *}$, Robert Cohen ${ }^{2,3,4,5,6}$, Xavier Durrmeyer ${ }^{1,3,7}$, Gilles Dassieu ${ }^{1}$, \\ Jérôme Barre ${ }^{4,8}$ and Laurence Caeymaex ${ }^{1,4,9}$
}

\begin{abstract}
${ }^{1}$ Neonatal Intensive Care Unit, Centre Hospitalier Intercommunal de Créteil, Créteil, France, ${ }^{2}$ ACTIV, Association Clinique et Thérapeutique Infantile du Val de Marne, Saint-Maur des Fossés, France, ${ }^{3}$ Université Paris Est, IMRB- GRC GEMINI, Créteil, France, ${ }^{4}$ Clinical Research Center, Centre Hospitalier Intercommunal de Créteil, Créteil, France, ${ }^{5}$ Groupe de Pathologie Infectieuse Pédiatrique, Paris, France, ${ }^{6}$ Unité Court Séjour, Petits Nourrissons, Service de Néonatologie, Centre Hospitalier Intercommunal de Créteil, Créteil, France, ${ }^{7}$ Inserm, U1153, Obstetrical, Perinatal and Pediatric Epidemiology Team, Epidemiology and Biostatistics Sorbonne, Paris Descartes University, Paris, France, ${ }^{8}$ Department of Pharmacology, Centre Hospitalier Intercommunal de Créteil, Créteil, France, ${ }^{9}$ Department of Research in Ethics EA1610 Studies on Science and Technics, Paris Est University, Créteil, France
\end{abstract}

OPEN ACCESS

Edited by:

Eric Giannoni,

Lausanne University Hospital

(CHUV), Switzerland

Reviewed by:

Karel Allegaert,

University Hospitals Leuven, Belgium

Chantal Csajka,

Lausanne University Hospital

(CHUV), Switzerland

${ }^{*}$ Correspondence:

Manon Tauzin

manon.tauzin@gmail.com

Specialty section:

This article was submitted to Pediatric Infectious Diseases,

a section of the journal

Frontiers in Pediatrics

Received: 18 December 2018 Accepted: 24 April 2019

Published: 14 May 2019

Citation:

Tauzin M, Cohen R, Durrmeyer $X$, Dassieu G, Barre J and Caeymaex L

(2019) Continuous-Infusion Vancomycin in Neonates: Assessment of a Dosing Regimen and Therapeutic

Proposal. Front. Pediatr. 7:188

doi: 10.3389/fped.2019.00188
Introduction: Vancomycin remains the reference antibiotic in neonates for care-related infections caused by B-lactam-resistant Gram-positive bacteria. Achieving the optimal serum vancomycin level is challenging because of high inter-individual variability and the drug's narrow therapeutic window. Continuous infusion might offer pharmacokinetic and practical advantages, but we lack consensus on the dosing regimen. The aim was to determine the proportion of neonates achieving an optimal therapeutic vancomycin level at the first vancomycin concentration assay and which dosing regimen is the most suitable for neonates.

Methods: All neonates receiving continuous-infusion vancomycin (loading dose $15 \mathrm{mg} / \mathrm{kg}$ and maintenance dose $30 \mathrm{mg} / \mathrm{kg} / \mathrm{d}$ ) in a neonatal intensive care unit were retrospectively analyzed. The proportion of neonates reaching the target serum vancomycin level was calculated. After reviewing the literature to identify all published articles proposing a dosing regimen for continuous-infusion vancomycin for neonates, regimens were theoretically applied to our population by using maintenance doses according to covariate(s) proposed in the original publication.

Results: Between January 2013 and December 2014, 75 neonates received 91 vancomycin courses by continuous infusion. Median gestational age, birth weight, and postnatal age were 27 weeks (interquartile range 26-30.5), $815 \mathrm{~g}(685-1,240)$, and 15 days (9-33). At the first assay, only 28/91 (30.8\%) courses resulted in vancomycin levels between 20 and $30 \mathrm{mg} / \mathrm{L}$ (target level), 23/91 (25.3\%) >30 mg/L and 40/91 (43.9\%) $<20 \mathrm{mg} / \mathrm{L}$. We applied six published dosing regimens to our patients. One of these dosing regimens based on corrected gestational age (CGA) and serum creatinine level (SCR) would have allowed us to prescribe lower doses to neonates with high vancomycin levels and higher doses to neonates with low levels. 
Conclusions: A simplified dosing regimen of continuous-infusion vancomycin did not achieve therapeutic ranges in neonates; a patient-tailored dosing regimen taking into account CGA and SCR level or an individualized pharmacokinetic model can help to anticipate the inter-individual variability in neonates and would have been more suitable.

Keywords: vancomycin, continuous-infusion, neonates, dosing, pharmacokinetics

\section{INTRODUCTION}

Vancomycin is a glycopeptide antibiotic frequently prescribed for neonatal care-related infections caused by Gram-positive bacteria such as coagulase-negative Staphylococci (CoNS), methicillin-resistant Staphylococcus aureus (MRSA), and Enterococci species (1). Because of the narrow therapeutic window and the lack of consensus on a toxicity threshold, determining the optimal dosing regimen for vancomycin is difficult, particularly for premature neonates, including those born before 28 weeks' gestation.

Vancomycin is a time-dependant antibiotic. It is sensitive to high inoculum effect and inhibited by biofilms (2). Its pharmacokinetics are characterized by an unbound fraction higher in neonates (about 90\%) than adults and children (3), a nearly total renal clearance correlated with creatinine clearance and a half life of 3.5 to $10 \mathrm{~h}(2,4)$. Vancomycin is administered intravenously because of its very low oral bioavailability. At all ages and even more so in neonates, the serum levels of vancomycin achieved feature high inter-individual variability (4). Covariates reported to influence its clearance are weight, gestational age (GA), corrected gestational age (CGA), post-natal age (PNA), co-medication with non-steroidal anti-inflammatory drugs, and serum creatinine (SCR) level, which could be interrelated $(4,5)$.

A ratio of $24-\mathrm{h}$ area under the curve $\left(\mathrm{AUC}_{0-24 \mathrm{~h}}\right)$ to minimum inhibitory concentration (MIC) $>400 \mathrm{mg} . \mathrm{h} / \mathrm{L}$ for total vancomycin is considered predictive of optimal antibacterial efficiency against MRSA in adults (6). This $\mathrm{AUC}_{0-24 \mathrm{~h}} / \mathrm{MIC}$ ratio is based on studies of adults using discontinuous infusion of vancomycin with a target trough level of 15 to $20 \mathrm{mg} / \mathrm{L}$ (7). In clinical practice, the $\mathrm{AUC}_{0-24 \mathrm{~h}} / \mathrm{MIC}$ ratio is difficult to estimate during discontinuous infusion (8) but is easy to estimate with steady-state levels during continuous infusion with the assumption that the level is relatively stable during infusion. For instance, for $S$. aureus infection [modal MIC $1 \mathrm{mg} / \mathrm{L}$, MIC breakpoint $2 \mathrm{mg} / \mathrm{L}$ (9)], a steady-state level of vancomycin $\geq 17$ $\mathrm{mg} / \mathrm{L}$ corresponds to an $\mathrm{AUC}_{0-24 \mathrm{~h}} / \mathrm{MIC}$ ratio $\geq 400 \mathrm{mg}$.h/L. Concerning CoNS infection, consistent data for neonates in an experimental animal model suggested an optimal efficacy of vancomycin and a decrease in induced resistance with an $\mathrm{AUC}_{0-24 \mathrm{~h}} / \mathrm{MIC}$ ratio $>400 \mathrm{mg} \cdot \mathrm{h} / \mathrm{L}$ (10). These data have not

\footnotetext{
Abbreviations: CoNS, coagulase-negative staphylococci; MRSA, methicillinresistant Staphylococcus aureus; GA, gestational age; CGA, corrected gestational age; PNA, post-natal age; SCR, serum creatinine; $\mathrm{AUC}_{0-24 \mathrm{~h}}, 24$-h area under the curve; MIC, minimum inhibitory concentration; NICU, neonatal intensive care unit; IUGR, intra-uterine growth restriction; EUCAST, European Committee on Antimicrobial Susceptibility Testing.
}

been validated in human neonates. For CoNS [modal MIC 2 $\mathrm{mg} / \mathrm{L}, \mathrm{MIC}$ breakpoint $4 \mathrm{mg} / \mathrm{L}(9)]$, a steady-state level of 33 $\mathrm{mg} / \mathrm{L}$ would be necessary to achieve an $\mathrm{AUC}_{0-24 \mathrm{~h}} / \mathrm{MIC}$ ratio $>400 \mathrm{mg} \cdot \mathrm{h} / \mathrm{L}$.

Because of the lack of consensus on efficacy and toxicity thresholds and an optimal dosing regimen, vancomycin dosing regimens between centers exhibit large heterogeneity (11). Continuous administration is controversal, notably in neonates, and data are mostly extrapolated from adult studies (12). Continuous administration requires a continuous availability of line but neonates, especially preterm neonates, often have a central catheter. Furthermore, vancomycin is stable for at least $48 \mathrm{~h}$ and compatible with parenteral nutrition (13) and the only one practical limitation can be drug incompatibilities. However, the major advantage of continuous infusion in neonates concomitant to parenteral nutrition is practical: preventing numerous catheter manipulations could decrease the risk of catheter-related infection (14). Therapeutic levels are achieved faster with continuous infusion, without clinical superiority as compared with discontinuous infusion $(15,16)$. Furthermore, with continuous infusion, fewer blood samples are required to adjust the optimal dosing regimen, possibly because therapeutic levels are achieved faster $(17,18)$. A steady-state level can be sampled at any time, for example, concomitant to a scheduled blood test, and is easier to interpret than trough levels $(17,19)$.

Few data are available on continuous infusion in neonates, particularly for premature infants born before 28 weeks' gestation (5). Different dosing regimens and different target levels have been proposed; with this heterogeneity, choosing an optimal dosing strategy in neonatology is difficult. Pharmacokinetics studies tend to develop individualized pharmacokinetic models with patient-tailored dosing regimens $(8,20)$.

The aim of this study was to assess the efficiency of a simplified dosing regimen of continuous-infusion vancomycin (loading dose $15 \mathrm{mg} / \mathrm{kg}$ and maintenance dose $30 \mathrm{mg} / \mathrm{kg} / \mathrm{d}$ ) in a neonatal intensive care unit (NICU) in neonates with suspected care-related infections caused by B-lactam-resistant Gram-positive bacteria. We assessed the proportion of neonates with serum vancomycin level achieving the chosen target with a first therapeutic drug monitoring. We then determined which dosing regimen, among those published, would have been the most adequate in our population.

\section{MATERIAL AND METHODS \\ Population and Collected Data}

We included all neonates receiving vancomycin with at least one serum vancomycin concentration assay between January 
2013 and December 2014 in the NICU of Center Hospitalier Intercommunal de Créteil (France). The following data were retrospectively collected from patient charts: GA in weeks (wks) based on the best obstetrical estimate, birth weight (g), intra-uterine growth restriction (IUGR, birth weight $<10$ th percentile for gestational age), sex, PNA in days (d), corrected gestational age (wks), current weight (g), SCR level $(\mu \mathrm{mol} / \mathrm{L})$ before treatment (quantified by the Jaffe method, Roche diagnostics, Indianapolis, IN, USA), serum vancomycin level $(\mathrm{mg} / \mathrm{L})$, delay between loading dose and blood sample (h), and microbiological data (results of blood cultures). No other consent than consent to usual standard care from parents was requested because the studied treatment was a standard of care. The local ethics committee of Créteil hospital approved the anonymous collection of data and their publication.

\section{Vancomycin Dosing Regimen}

Vancomycin was administered by continuous infusion via a central or peripheral catheter starting with a loading dose of 15 $\mathrm{mg} / \mathrm{kg}$ over $1 \mathrm{~h}$ followed by a maintenance dose of $30 \mathrm{mg} / \mathrm{kg} / \mathrm{d}$ (21). A blood sample was drawn at least $18 \mathrm{~h}$ after the loading dose to reach the steady state (20). Serum vancomycin level was determined by the immunoturbidimetric technique (QMS system of Vancomycin, Seradyn Inc., Indianapolis, IN, USA). If the target level was not reached in the first sample, the maintenance dose was adjusted according to clinicians' choice and a new vancomycin assay was performed at least $24 \mathrm{~h}$ after dose adjustment until the target level of 20 to $30 \mathrm{mg} / \mathrm{L}$ was achieved.

\section{Assessed Outcomes}

Our first goal was to determine the proportion of neonates reaching the target serum vancomycin level and to identify independent covariates associated with low or high therapeutic levels. The target level used was 20 to $30 \mathrm{mg} / \mathrm{L}$ (19).

Our second objective was to assess different continuousinfusion regimens proposed in the literature as applied to our population. We determined whether each proposed regimen would have resulted in a significantly higher, equal or lower vancomycin dose within each subgroup of our population: infants with a first therapeutic drug monitoring $<20 \mathrm{mg} / \mathrm{L}$ (underdose), 20 to $30 \mathrm{mg} / \mathrm{L}$ (appropriate dose), and $>30 \mathrm{mg} / \mathrm{L}$ (overdose). For each patient, we used the covariate(s) proposed in the original publication.

\section{Literature Search}

MEDLINE was searched via PubMed to identify all published articles proposing a dosing regimen for continuous-infusion vancomycin for neonates. The search was conducted in August 2018 with the following terms: neonates AND vancomycin AND (dosing OR continuous). We selected English-language articles that proposed a detailed dosing regimen for continuous infusion of vancomycin in neonates that could be reproduced in our population.

\section{Statistical Analysis}

The association between vancomycin levels and variables (GA, birth weight, PNA, CGA, current weight, IUGR, sex, timing of assay, and SCR level) was analyzed by using R 3.3.2 (http://www. $\mathrm{R}$-project.org). To facilitate results' interpretation for clinicians, continuous variables were separated into dichotomous variables with cut-offs set according to the literature and commonly used categories: GA $<$ or $\geq 28$ weeks (22), CGA $<$ or $\geq 32$ weeks (22), neonate weight $\leq$ or $>1,000 \mathrm{~g}$ (23), PNA $\leq$ or $>14$ days $(24,25)$, timing of assay $\leq 24 \mathrm{~h}$ or $>24 \mathrm{~h}$ (20), and SCR level $<$ or $\geq 70 \mu \mathrm{mol} / \mathrm{L}(20,21)$. Descriptive data are described with median and interquartile range (IQR) or mean (SD). Chisquare or Fisher exact test was used to determine covariates with significantly different distribution among vancomycin level subgroups (low level, target level, and high level). $P \leq 0.05$ was considered statistically significant. Covariates with $p<0.1$ on univariate analysis were included in a multivariate analysis. We used multinomial logistic regression to determine covariates independently related to low and high levels as compared with the target level $(p<0.05)$, estimating adjusted odds ratios (aOR) and $95 \%$ confidence intervals (CIs).

TABLE 1 | Demographic and clinical characteristics of neonates $(n=75)$ under continuous infusion with vancomycin ( $n=91$ therapy episodes) for care-related infections caused by ß-lactam-resistant Gram-positive bacteria.

\begin{tabular}{|c|c|c|}
\hline & $N(\%)$ & Median [IQR] \\
\hline Gestational age (weeks) & & 27 [26-30.5] \\
\hline$<28$ & $40(53.3)$ & \\
\hline$\geq 28$ & $35(46.7)$ & \\
\hline Birth weight (g) & & $815[685-1,240]$ \\
\hline$\leq 1,000$ & $41(54.7)$ & \\
\hline$>1,000$ & $34(45.3)$ & \\
\hline Intrauterine growth restriction & $33(44)$ & \\
\hline \multicolumn{3}{|l|}{ Sex } \\
\hline Male & $43(57.3)$ & \\
\hline Female & $32(42.7)$ & \\
\hline Postnatal age (d) & & 15 [9-33] \\
\hline$\leq 14$ & $42(46.2)$ & \\
\hline$>14$ & $49(53.8)$ & \\
\hline $\begin{array}{l}\text { Corrected gestational age } \\
\text { (weeks) }\end{array}$ & & 30 [28-34.5] \\
\hline$<32$ & $52(57.2)$ & \\
\hline$\geq 32$ & $39(42.8)$ & \\
\hline Current weight (g) & & $1,230[940-1,790]$ \\
\hline$\leq 1,000$ & $30(33)$ & \\
\hline$>1,000$ & $61(67)$ & \\
\hline $\begin{array}{l}\text { Serum creatinine level before } \\
\text { treatment }(\mu \mathrm{mol} / \mathrm{L})(n=68)\end{array}$ & & 52 [26.5-70] \\
\hline$>70$ & $17(25)$ & \\
\hline$\leq 70$ & $51(75)$ & \\
\hline First vancomycin level (mg/L) & & 21.1 [16.3-29.7] \\
\hline $\begin{array}{l}\text { Number of samples per } \\
\text { treatment }\end{array}$ & & $2[1-2.5]$ \\
\hline Time of first sampling (h) & & 25.5 [23.9-33.3] \\
\hline Treatment duration (d) & & $4[3-7]$ \\
\hline
\end{tabular}


To compare doses proposed by each dosing regimen reported in the literature with actual doses given to our patients, we used Student $t$-test and report mean differences and $95 \%$ CIs.

\section{RESULTS}

\section{Population}

From January 2013 to December 2014, 75 neonates received 99 vancomycin courses by continuous infusion. Eight treatments were excluded because the neonates did not receive the dosing regimen evaluated. Patient characteristics are summarized in Table 1. Median gestational age and birth weight were 27 weeks (IQR 26-30.5) and $815 \mathrm{~g}$ (IQR 685-1,240); 40/75 neonates (53.3\%) were born before 28 weeks' GA. Overall, 184 serum vancomycin samples were assayed, with a median of 2 (IQR 12.5) determinations per patient. A first blood sample was taken 18.5 to $93.5 \mathrm{~h}$ after the loading dose. SCR level before treatment was available for 68 patients and ranged from 15 to $116 \mu \mathrm{mol} / \mathrm{L}$; for $17 / 68$ (25\%) neonates, the SCR level was $>70 \mu \mathrm{mol} / \mathrm{L}$.

\section{Microbiological Data}

For 24/91 (26.4\%) courses, at least one blood culture was positive: $17 / 91$ only one positive blood culture and 7/91 (7.7\%) at least two positive blood cultures. Most $(67 / 91 ; 73.6 \%)$ had negative blood cultures. Bacterial species found were CoNS (17/91; 18.7\%), S. aureus $(3 / 91 ; 3.3 \%)$ with one MRSA, Streptococcus sp. $(2 / 91$; $2.2 \%)$, Escherichia coli $(1 / 91 ; 1 \%)$, and Streptococcus pneumoniae $(1 / 91 ; 1.1 \%)$. The distribution of CoNS was $S$. epidermidis $(n=10)$, S. haemoliticus $(n=2)$, and S. capitis $(n=5)$.

\section{Serum Vancomycin Levels}

Vancomycin serum levels ranged from 6.9 to $60.3 \mathrm{mg} / \mathrm{L}$. For $28 / 91$ (30.8\%) courses, a level of 20 to $30 \mathrm{mg} / \mathrm{L}$ was achieved in the first assay; 40/91 (43.9\%) had low therapeutic levels, $<20 \mathrm{mg} / \mathrm{L}$, and $23 / 91$ (25.3\%) had levels $>30 \mathrm{mg} / \mathrm{L}$. For seven $(7.7 \%)$, the level was $>40 \mathrm{mg} / \mathrm{L}$. Vancomycin levels on time are displayed in Figure 1. A total of 49 neonates had a second sample assayed and for $18 / 49(36.7 \%)$, serum levels were at the chosen target; three retained a level $>40 \mathrm{mg} / \mathrm{L}$. At the first assay or after dose titration, for 56/91 (61.5\%) courses, the therapeutic level between 20 and $30 \mathrm{mg} / \mathrm{L}$ was reached. For those neonates, the median time to achieving a therapeutic level was $34 \mathrm{~h}$ (IQR 24.5-74.5).

\section{Covariates Analysis}

On univariate analysis, we identified five covariates significantly related to vancomycin serum levels: PNA $(p=0.001)$, sex $(p=0.05)$, CGA $(p=0.004)$, current weight $(p=0.04)$, and SCR level ( $p<0.0001)$ (Table 2). On multivariate analysis, only three of these covariates remained significantly associated with serum vancomycin level: PNA $>14$ days $(\mathrm{aOR}=25.6$, 95\% CI [3.2201.5], $p=0.002$ ) and CGA $\geq 32$ weeks were related to low level $(\mathrm{aOR}=48.2,95 \% \mathrm{CI}[7.0-334.6], p<0.001)$ and SCR level $>$ $70 \mu \mathrm{mol} / \mathrm{L}$ was associated with high level $(\mathrm{aOR}=33.0,95 \% \mathrm{CI}$ [4.0-272.6], $p=0.001$ ). There was no association between timing of vancomycin assay and vancomycin serum levels $(p=0.4)$ (Table 2 and Figure 1).

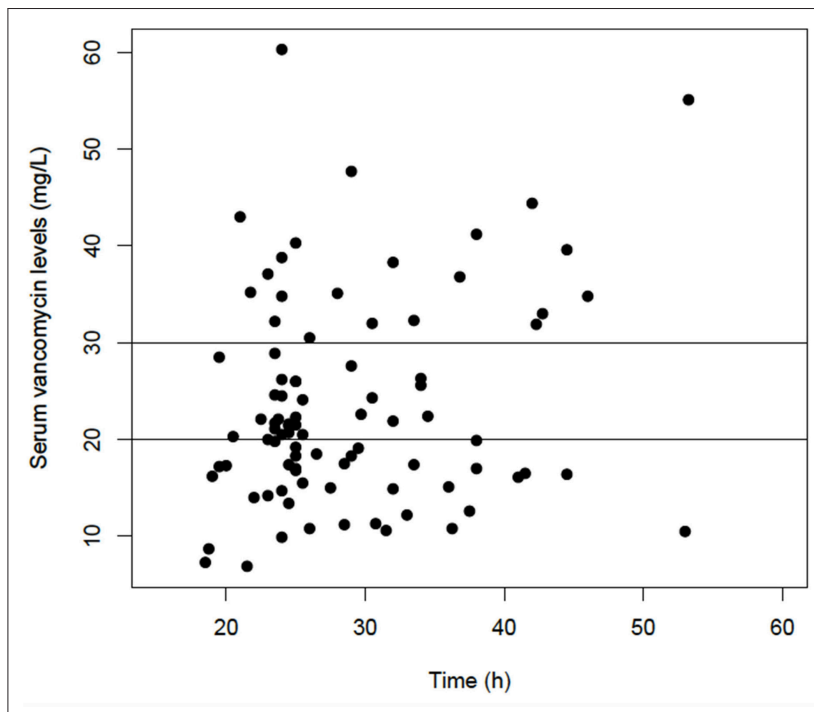

FIGURE 1 | Serum vancomycin level (mg/L) on time (h). Horizontal lines represent the target level of 20 to $30 \mathrm{mg} / \mathrm{L}$.

\section{Literature Search}

The search algorithm identified 146 studies in Pubmed (144 after removal of duplicates): 51 referred to discontinuous infusion of vancomycin; 29 did not propose a detailed dosing schedule of vancomycin; 40 did not address our subject; 10 were not in English; six proposed a dosing schedule for neonates on extracorporeal life support or intraventricular injection; and two presented a preventive dosing regimen. Finally, six studies detailed different dosing regimens of continuous-infusion vancomycin for neonates (Table 3). Five studies agreed on a loading dose of 7 to $20 \mathrm{mg} / \mathrm{kg}$ to quickly reach target levels $(15,20,21,26,28)$. Maintenance doses ranged from 10 to 60 $\mathrm{mg} / \mathrm{kg} / \mathrm{d}$, with a unique dose of $30 \mathrm{mg} / \mathrm{kg} / \mathrm{d}$ (21) or a dose adjusted to SCR level, CGA, birth weight, current body weight, and/or PNA $(15,20,26-28)$. The proportion of patients achieving the chosen target level of 10 to $30 \mathrm{mg} / \mathrm{L}(21,26), 10$ to $25 \mathrm{mg} / \mathrm{L}$ (27) or 15 to $25 \mathrm{mg} / \mathrm{L}(15,20)$ were $70.7 \%(20), 75 \%(27), 77 \%$ (15), $88 \%$ (26), $89.2 \%$ (21), respectively.

\section{Dosing Regimen From the Literature Applied to Our Population}

We compared mean doses and mean differences between our maintenance dose $(30 \mathrm{mg} / \mathrm{kg} / \mathrm{d})$ and maintenance dose proposed by each dosing regimen from the literature (Table 4).

Three dosing regimen from the literature would have proposed significantly higher vancomycin doses to neonates with a low vancomycin level, $<20 \mathrm{mg} / \mathrm{L}$ : mean dose (SD) of 36.4 (8.1) $\mathrm{mg} / \mathrm{kg} / \mathrm{d}$ (27), 38.5 (9.5) $\mathrm{mg} / \mathrm{kg} / \mathrm{d}$ (15), and 48.5 (20) $\mathrm{mg} / \mathrm{kg} / \mathrm{d}(20)$. Two dosing regimens would have proposed the same dose: mean dose (SD) of $30(0) \mathrm{mg} / \mathrm{kg} / \mathrm{d}(21,27)$. One dosing regimen would have proposed lower doses to neonates with low vancomycin level: mean dose (SD) of $20.6(6.5) \mathrm{mg} / \mathrm{kg} / \mathrm{d}$ (26) (Table 4). 
TABLE 2 | Distribution of covariates by vancomycin level.

\begin{tabular}{|c|c|c|c|c|}
\hline \multirow[t]{2}{*}{ Covariates } & \multicolumn{4}{|c|}{ Vancomycin level (mg/L) } \\
\hline & $<20$ & 20-30 & $>30$ & $p$-value \\
\hline \multicolumn{5}{|l|}{ Gestational age (wks) } \\
\hline$<28$ & 19 & 17 & 16 & 0.16 \\
\hline$\geq 28$ & 21 & 12 & 6 & \\
\hline \multicolumn{5}{|l|}{ Birth weight (g) } \\
\hline$\leq 1,000$ & 24 & 17 & 12 & 0.9 \\
\hline$>1,000$ & 16 & 12 & 10 & \\
\hline \multicolumn{5}{|c|}{ Intra-uterine growth restriction } \\
\hline Absence & 18 & 16 & 13 & 0.5 \\
\hline Presence & 22 & 13 & 9 & \\
\hline \multicolumn{5}{|l|}{ Sex } \\
\hline Male & 18 & 16 & 17 & 0.05 \\
\hline Female & 22 & 13 & 5 & \\
\hline \multicolumn{5}{|l|}{ Postnatal age (d) } \\
\hline$\leq 14$ & 10 & 17 & 15 & 0.001 \\
\hline$>14$ & 30 & 12 & 7 & \\
\hline \multicolumn{5}{|c|}{ Corrected gestational age (wks) } \\
\hline$<32$ & 21 & 21 & 15 & 0.004 \\
\hline$\geq 32$ & 8 & 8 & 25 & \\
\hline \multicolumn{5}{|l|}{ Current weight (g) } \\
\hline$\leq 1,000$ & 8 & 11 & 11 & 0.04 \\
\hline$>1,000$ & 32 & 18 & 11 & \\
\hline \multicolumn{5}{|c|}{ Serum creatinine level $(\mu \mathrm{mol} / \mathrm{L})$} \\
\hline$\leq 70$ & 25 & 20 & 6 & $<0.0001$ \\
\hline$>70$ & 2 & 3 & 12 & \\
\hline Time of first sampling (h) & & & & 0.4 \\
\hline$\leq 24$ & 11 & 12 & 7 & \\
\hline$>24$ & 29 & 16 & 15 & \\
\hline
\end{tabular}

For patients with a vancomycin level in the target range (20-30 $\mathrm{mg} / \mathrm{L}$ ), four dosing regimens would have proposed similar doses as the actual dose given to our patients: mean dose (SD) of 30 (0) $(21,27), 30.8$ (8.1) (20), and $31.4(8.3)(15) \mathrm{mg} / \mathrm{kg} / \mathrm{d}$. One would have proposed significantly lower doses: mean dose (SD) of 16.1 (4.6) $\mathrm{mg} / \mathrm{kg} / \mathrm{d}$ (26) and one significantly higher doses: mean dose (SD) of 32.2 (5.6) $\mathrm{mg} / \mathrm{kg} / \mathrm{d}$ (28) (Table 4).

For patients with a high vancomycin level, $>30 \mathrm{mg} / \mathrm{L}$, three dosing regimens would have proposed significantly lower doses: mean dose (SD) of 22.6 (7.3) (15), 15.7 (6.8) (26), and 24.4 (5.1) (27) $\mathrm{mg} / \mathrm{kg} / \mathrm{d}$. Two would have proposed similar doses [25.4 (12.8) (20), and $30(0) \mathrm{mg} / \mathrm{kg} / \mathrm{d}(21)]$ and one significantly higher doses [33.8 (6.4) mg/kg/d (28)] (Table 4).

Finally, one dosing algorithm (15) would have proposed lower doses to patients with high levels, similar doses to those with levels in the target range and higher doses to those with low levels (Table 4).

\section{DISCUSSION}

This study presents a cohort of premature neonates receiving continuous infusion of vancomycin and is the first study comparing the six dosing regimens reported in the literature for neonates. We evaluated the proportion of patients reaching the therapeutic vancomycin range. With the dosing regimen used in our department (loading dose of $15 \mathrm{mg} / \mathrm{kg}$ and maintenance dose of $30 \mathrm{mg} / \mathrm{kg} / \mathrm{d}$ ), only $30.8 \%$ of neonates achieved target vancomycin levels of 20 to $30 \mathrm{mg} / \mathrm{L}, 43.9 \%$ had low therapeutic levels and $25.3 \%$ had levels $>30 \mathrm{mg} / \mathrm{L}$. These disappointing results confirm that a simplified regimen does not fit a population of neonates characterized by high inter-individual variability and the important pharmacokinetic changes in the first weeks of life (kidney maturation and changes in volume of distribution) (4).

After comparing dosing regimens proposed in the literature, the dosing regimen proposed by Patel et al. seemed the most adequate for our population. This model is easy to apply and includes cofactors of variability such as SCR level and CGA. Applied to our neonates with a target level of 20 to $30 \mathrm{mg} / \mathrm{L}$, the model proposed significantly lower doses to neonates with high vancomycin levels and higher doses to those with low therapeutic levels. The individualized pharmacokinetic model proposed by Zhao et al. would also propose more appropriate doses to a large proportion of neonates. Indeed, it proposed significantly higher doses to neonates with low levels and lower doses to those with high levels (even if not significant, $p=0.13$ ). This model can be adjusted to the chosen target level, which is an advantage when the clinician wants to adjust the target level to the MIC. In a previous study, a prospective validation of this model with 190 neonates showed that $72 \%$ reached the target level (15-25 mg/L) at the first therapeutic drug monitoring (29). The other evaluated dosing regimens proposed lower doses, even for patients with already low therapeutic levels (26), or higher doses, even for patients with already high levels (28). Those dosing regimen do not fit our population. An explanation could be the differences between vancomycin and serum creatinine measurement methods as demonstrated in some studies (30).

Concerns have been raised about the efficacy threshold of target concentrations because of increased vancomycin MICs with CoNS infection (4) and toxicity issues. According to the European Committee on Antimicrobial Susceptibility Testing (9), the modal MIC is $2 \mathrm{mg} / \mathrm{L}$ for CoNS and $1 \mathrm{mg} / \mathrm{L}$ for $S$. aureus infections. To reach the $\mathrm{AUC}_{0-24 \mathrm{~h}} / \mathrm{MIC}$ ratio $>400 \mathrm{mg} . \mathrm{h} / \mathrm{L}$ as advised, a steady-state level $>33 \mathrm{mg} / \mathrm{L}$ for CoNS infection and $>17 \mathrm{mg} / \mathrm{L}$ for $S$. aureus infection would be needed to reach optimal efficiency and limit resistance $(2,18,21) . S$. aureus infections are characterized by severe clinical presentation and metastatic risk (31). CoNS infections, with central line catheters, are rarely metastatic and have less severe clinical and biological presentations, but therapeutic failure can be attributed in part to biofilms produced (32). Moreover, the $\mathrm{AUC}_{0-24 \mathrm{~h}} / \mathrm{MIC}$ target $>400 \mathrm{mg}$.h/L was developed for MRSA infections, so a CoNS-specific pharmacodynamic target should be established, especially for neonates (33). Hence, for CoNS, an initial level $<30$ $\mathrm{mg} / \mathrm{L}$ could be sufficient despite a high MIC.

Concerning the upper threshold of the target concentration, a study of adults showed an $\mathrm{AUC}_{0-24 \mathrm{~h}}>1,300 \mathrm{mg} \cdot \mathrm{h} / \mathrm{L}$, corresponding to a steady-state level $>55 \mathrm{mg} / \mathrm{L}$, associated with increased risk of nephrotoxicity (34). Adult and pediatric studies suggest that without reaching such high levels, an upper 
TABLE 3 | Proposed dosing regimens from the literature.

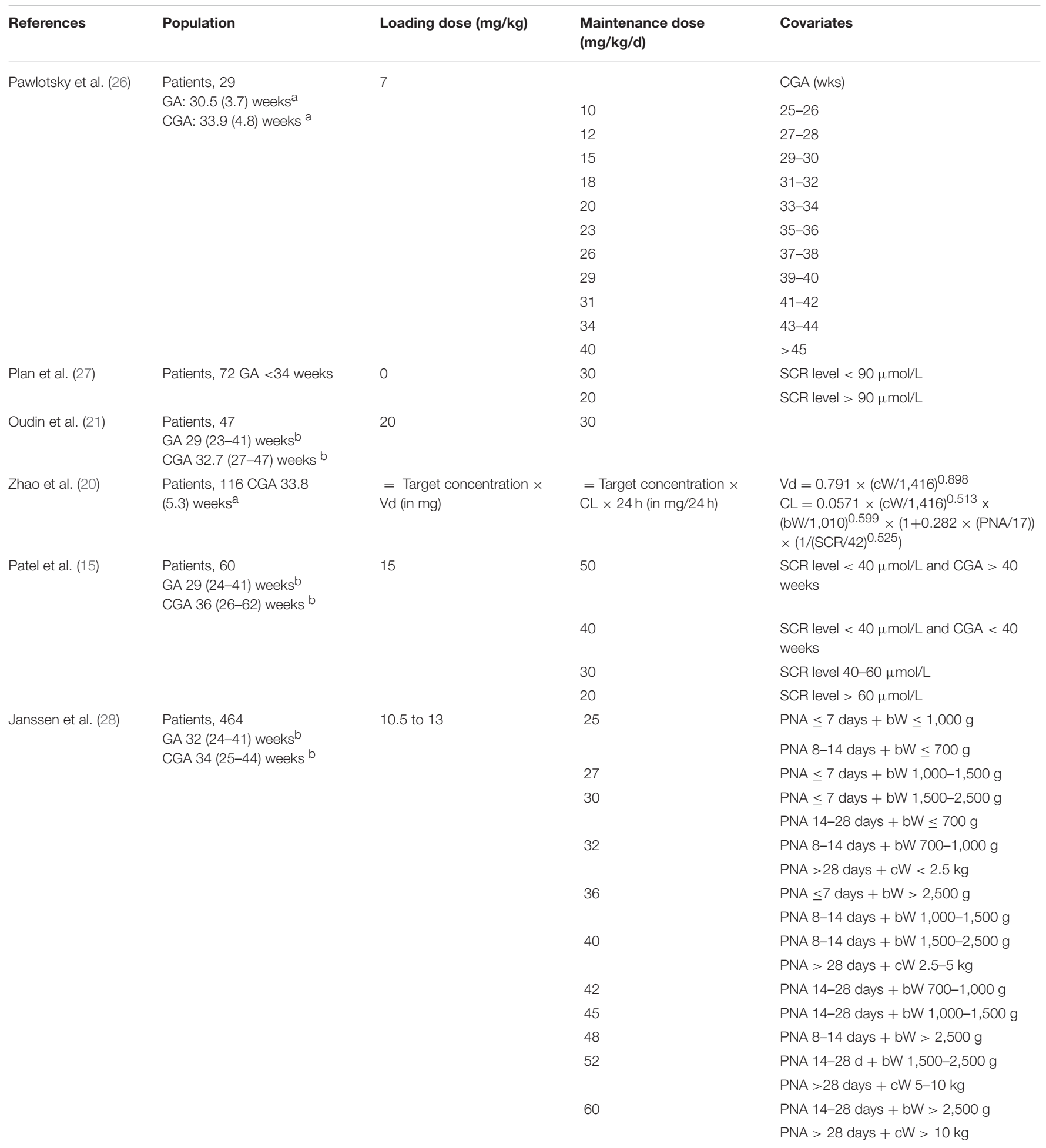

GA, gestational age; CGA, corrected gestational age; SCR, serum creatinine; Vd, volume of distribution; CL, clearance; $C W$, current weight; bW, birth weight; PNA, post natal age. ${ }^{a}$ Mean (SD).

${ }^{b}$ Median (range). 
TABLE 4 | Mean doses and mean differences (95\% Cls) proposed by the six dosing regimens evaluated for each group of patients (low, target and high vancomycin levels).

\begin{tabular}{|c|c|c|c|c|}
\hline Dosing regimen & & $\begin{array}{l}\text { Low level } \\
(<20 \mathrm{mg} / \mathrm{L}) \\
(n=40)\end{array}$ & $\begin{array}{l}\text { Target level } \\
(20-30 \mathrm{mg} / \mathrm{L}) \\
(n=28)\end{array}$ & $\begin{array}{c}\text { High level } \\
\text { (>30 mg/L) } \\
(n=23)\end{array}$ \\
\hline \multirow[t]{3}{*}{ Our dosing regimen } & Mean dose (SD) & $30(0)$ & $30(0)$ & $30(0)$ \\
\hline & Mean difference (95\% Cl) & - & - & - \\
\hline & $P$-value ${ }^{\mathrm{a}}$ & - & - & - \\
\hline \multirow[t]{3}{*}{ Pawlotsky et al.(26) } & Mean dose (SD) & $20.6(6.5)$ & $16.1(4.6)$ & $15.7(6.8)$ \\
\hline & Mean difference $(95 \% \mathrm{Cl})$ & $-9.4(-11.5$ to -7.4$)$ & $-13.9(-15.6$ to -12.1$)$ & $-14.3(-11.4$ to -17.2$)$ \\
\hline & $P$-value ${ }^{a}$ & $<0.001$ & $<0.001$ & $<0.001$ \\
\hline \multirow[t]{3}{*}{ Plan et al. (27) } & Mean dose (SD) & $30(0)$ & $30(0)$ & $24.4(5.1)$ \\
\hline & Mean difference (95\% Cl) & 0 & 0 & $-5.6(-8.3$ to -2.9$)$ \\
\hline & $P$-value ${ }^{a}$ & - & - & $<0.001$ \\
\hline \multirow[t]{3}{*}{ Oudin et al. (21) } & Mean dose (SD) & $30(0)$ & $30(0)$ & $30(0)$ \\
\hline & Mean difference (95\% Cl) & 0 & 0 & 0 \\
\hline & $P$-value ${ }^{\mathrm{a}}$ & - & - & - \\
\hline \multirow[t]{3}{*}{ Zhao et al. (20) } & Mean dose (SD) & $48.5(20)$ & $30.8(8.1)$ & $25.4(12.8)$ \\
\hline & Mean difference $(95 \% \mathrm{Cl})$ & 18.5 (10.7 to 26.4$)$ & $0.8(-2.8$ to 4.4$)$ & $-4.6(-10.7$ to 1.5$)$ \\
\hline & $P$-value ${ }^{a}$ & $<0.001$ & 0.63 & 0.13 \\
\hline \multirow[t]{3}{*}{ Patel et al. (15) } & Mean dose (SD) & $38.5(9.5)$ & $31.4(8.3)$ & $22.6(7.3)$ \\
\hline & Mean difference (95\% Cl) & 8.5 (4.8 to 12.3$)$ & $1.4(-2.3$ to 5.1$)$ & $-7.4(-10.9$ to -3.8$)$ \\
\hline & $P$-value ${ }^{a}$ & $<0.001$ & 0.45 & $<0.001$ \\
\hline \multirow[t]{3}{*}{ Janssen et al. (28) } & Mean dose (SD) & $36.4(8.1)$ & $32.2(5.6)$ & $33.8(6.4)$ \\
\hline & Mean difference $(95 \% \mathrm{Cl})$ & 6.4 (3.8 to 9.0) & $2.2(0.1$ to 4.4$)$ & 3.8 (1.0 to 6.6$)$ \\
\hline & $P$-value ${ }^{a}$ & $<0.001$ & 0.04 & 0.009 \\
\hline
\end{tabular}

a Student $t$-test comparing mean dose of our dosing algorithm with mean dose of each dosing regimen.

95\% Cl, 95\% confidence interval.

threshold might be about $30 \mathrm{mg} / \mathrm{L}$ (35) $\left(\mathrm{AUC}_{0-24 \mathrm{~h}} 700 \mathrm{mg} . \mathrm{h} / \mathrm{L}\right)$, which might be increased to $37.5 \mathrm{mg} / \mathrm{L}\left(\mathrm{AUC}_{0-24 \mathrm{~h}} 900 \mathrm{mg} \cdot \mathrm{h} / \mathrm{L}\right)$, an adequate threshold in terms of risk for bacteria with a MIC of $2 \mathrm{mg} / \mathrm{L}(36,37)$. In our study, for two neonates, the SCR level was higher after than before treatment, but linking the accountability to vancomycin was difficult (one neonate in a context of perinatal asphyxia and the other with multiorgan failure in a context of extreme prematurity). Studies of vancomycin-associated nephrotoxicity in neonatology conclude that the condition is rare and reversible and proof of a dose-toxicity relationship is lacking, even with levels $>30 \mathrm{mg} / \mathrm{L}$ or associated with an aminoglycoside (38). However, careful monitoring should be carried out especially in high-risk neonates with nephrotoxic comedication (non-steroidal anti-inflammatory drugs, diuretics), with low birth weight or with severe illness (sepsis, patent ductus arteriosus).

CGA and high SCR level have been linked to interindividual variability in vancomycin levels, along with other covariates such as weight, PNA, GA, ventilation type, and co-treatments (4). However, residual variability remains despite accounting for these factors. Thus, therapeutic drug monitoring still seems necessary. The usual timing for vancomycin drug monitoring is at least 18 to $24 \mathrm{~h}$ after the initation or modification of treatment (20). Dosing adjustment was not satisfactory in our study, with $63 \%$ of levels in secondary samples remaining outside of the target. A method based on a linear relationship between the maintenance dose and steady-state level has been proposed: adjusted dose $=$ maintenance dose $\times$ target level/last vancomycin level $(19,20)$.

Our study has several limitations. First, it was a retrospective study that can imply imprecision in recorded data. Second, SCR level was available before treatment for only threequarters of the neonates, which prevented us from applying published dosing regimens to all our patients. Following this study, creatinine measurement became mandatory to manage vancomycin treatment in our department. Another limitation is the lack of documentation of MICs of bacteria, with $74 \%$ of blood cultures remaining negative. Therefore, we could not evaluate the proportion of MICs $>1 \mathrm{mg} / \mathrm{L}$ that would require higher vancomycin levels. Finally, even if other studies already described the use of continuous infusion vancomycin in neonates, our cohort mainly contained extremely premature neonates $<28$ weeks' GA, a very challenging population.

\section{CONCLUSIONS}

Continuous-infusion vancomycin for neonates offers a practical and pharmacokinetic interest. The use of a dosing regimen taking into account CGA and SCR level or an individualized 
pharmacokinetic model can help to anticipate the interindividual variability in neonates and seems more adapted than a simplified dosing regimen. Validation of a dosing regimen in a controlled trial with a large number of patients would allow to evaluate performances in achieving target levels and for better assessment of short- and long-term toxicity. Despite a patient-tailored dosing regimen, therapeutic drug monitoring still seems necessary.

\section{ETHICS STATEMENT}

The local ethics committee of Créteil hospital approved the anonymous collection of data and their publication.

\section{REFERENCES}

1. Lutsar I, Chazallon C, Carducci FIC, Trafojer U, Abdelkader B, de Cabre VM, et al. Current management of late onset neonatal bacterial sepsis in five European countries. Eur J Pediatr. (2014) 173:997-1004. doi: 10.1007/s00431-014-2279-5

2. Vandecasteele SJ, De Vriese AS, Tacconelli E. The pharmacokinetics and pharmacodynamics of vancomycin in clinical practice: evidence and uncertainties. J Antimicrob Chemother. (2013) 68:743-8. doi: $10.1093 / \mathrm{jac} / \mathrm{dks} 495$

3. Smits A, Pauwels S, Oyaert M, Peersman N, Spriet I, Saegeman V, et al. Factors impacting unbound vancomycin concentrations in neonates and young infants. Eur J Clin Microbiol Infect Dis. (2018) 37:1503-10. doi: 10.1007/s10096-018-3277-8

4. de Hoog M, Mouton JW, van den Anker JN. Vancomycin: pharmacokinetics and administration regimens in neonates. Clin Pharmacokinet. (2004) 43:41740. doi: 10.2165/00003088-200443070-00001

5. Pacifici GM, Allegaert K. Clinical pharmacokinetics of vancomycin in the neonate: a review. Clin São Paulo Braz. (2012) 67:831-7. doi: 10.6061/clinics/2012(07)21

6. Frymoyer A, Hersh AL, El-Komy MH, Gaskari S, Su F, Drover DR, et al. Association between vancomycin trough concentration and area under the concentration-time curve in neonates. Antimicrob Agents Chemother. (2014) 58:6454-61. doi: 10.1128/AAC.03620-14

7. Liu C, Bayer A, Cosgrove SE, Daum RS, Fridkin SK, Gorwitz RJ, et al. Clinical practice guidelines by the infectious diseases society of America for the treatment of methicillin-resistant Staphylococcus aureus infections in adults and children: executive summary. Clin Infect Dis Off Publ Infect Dis Soc Am. (2011) 52:285-92. doi: 10.1093/cid/cir034

8. Jacqz-Aigrain E, Leroux S, Zhao W, van den Anker JN, Sharland M. How to use vancomycin optimally in neonates: remaining questions. Expert Rev Clin Pharmacol. (2015) 8:635-48. doi: 10.1586/17512433.2015.1060124

9. European Committee on Antimicrobial Susceptibility Testing (EUCAST). (2017). Available online at: http://mic.eucast.org/consultéenseptembre; http:// www.eucast.org/mic_distributions_and_ecoffs/

10. Ramos-Martín V, Johnson A, Livermore J, McEntee L, Goodwin J, Whalley S. Pharmacodynamics of vancomycin for CoNS infection: experimental basis for optimal use of vancomycin in neonates. J Antimicrob Chemother. (2016) 71:992-1002. doi: 10.1093/jac/dkv451

11. Leroux S, Zhao W, Biran V, Jacqz-Aigrain E. Posologie des antibiotiques chez le nouveau-né : variations des pratiques et comment y remédier e Arch Pédiatr. (2016) 23:966-73. doi: 10.1016/j.arcped.2016.06.002

12. Ward RM, Allegaert K, de Groot R, van den Anker JN. Commentary: continuous infusion of vancomycin in neonates: to use or not to use remains the question. Pediatr Infect Dis J. (2014) 33:606-7. doi: 10.1097/INF.0000000000000244

13. Raverdy V, Ampe E, Hecq J-D, Tulkens PM. Stability and compatibility of vancomycin for administration by continuous infusion. J Antimicrob Chemother. (2013) 68:1179-82. doi: 10.1093/jac/dks510

\section{AUTHOR CONTRIBUTIONS}

MT and RC designed and conducted the study. MT collected and analyzed patient data. MT, RC, XD, and LC interpreted results. MT wrote the manuscript with major contributions by RC and reviewing by LC, XD, GD, and JB. All authors read and approved the final manuscript.

\section{ACKNOWLEDGMENTS}

We thank Stéphane Bechet and Dr. Corinne Levy (ACTIV) for technical support and Dr. Claude Danan and Dr. Fabrice Decobert for advice.

14. Stevens TP, Schulman J. Evidence-based approach to preventing central line-associated bloodstream infection in the NICU: evidence-based approach to preventing NICU CLABSI. Acta Paediatr. (2012) 101:11-6. doi: 10.1111/j.1651-2227.2011.02547.x

15. Patel AD, Anand D, Lucas C, Thomson AH. Continuous infusion of vancomycin in neonates. Arch Dis Child. (2013) 98:478-9. doi: 10.1136/archdischild-2012-303197

16. Kim J, Walker SAN, Iaboni DC, Walker SE, Elligsen M, Dunn MS, et al. Determination of vancomycin pharmacokinetics in neonates to develop practical initial dosing recommendations. Antimicrob Agents Chemother. (2014) 58:2830-40. doi: 10.1128/AAC.01718-13

17. Saugel B, Nowack MCM, Hapfelmeier A, Umgelter A, Schultheiss C, Thies $\mathrm{P}$, et al. Continuous intravenous administration of vancomycin in medical intensive care unit patients. J Crit Care. (2013) 28:9-13. doi: $10.1016 /$ j.jcrc.2012.02.003

18. Wysocki M, Delatour F, Faurisson F, Rauss A, Pean Y, Misset $\mathrm{B}$, et al. Continuous versus intermittent infusion of vancomycin in severe staphylococcal infections: prospective multicenter randomized study. Antimicrob Agents Chemother. (2001) 45:2460-7. doi: 10.1128/AAC.45.9.2460-2467.2001

19. Waineo MF, Kuhn TC, Brown DL. The pharmacokinetic/pharmacodynamic rationale for administering vancomycin via continuous infusion. J Clin Pharm Ther. (2015) 40:259-65. doi: 10.1111/jcpt.12270

20. Zhao W, Lopez E, Biran V, Durrmeyer X, Fakhoury M, Jacqz-Aigrain E. Vancomycin continuous infusion in neonates: dosing optimisation and therapeutic drug monitoring. Arch Dis Child. (2013) 98:449-53. doi: 10.1136/archdischild-2012-302765

21. Oudin C, Vialet R, Boulamery A, Martin C, Simon N. Vancomycin prescription in neonates and young infants: toward a simplified dosage. Arch Dis Child Fetal Neonatal Ed. (2011) 96:F365-70. doi: 10.1136/adc.2010.196402

22. Blencowe H, Cousens S, Oestergaard MZ, Chou D, Moller A-B, Narwal R, et al. National, regional, and worldwide estimates of preterm birth rates in the year 2010 with time trends since 1990 for selected countries: a systematic analysis and implications. Lancet Lond Engl. (2012) 379:2162-72. doi: 10.1016/S0140-6736(12)60820-4

23. Gross JR, Kaplan SL, Kramer WG, Mason EO. Vancomycin pharmacokinetics in premature infants. Pediatr Pharmacol N Y N. (1985) 5:17-22.

24. Dersch-Mills D, Bengry T, Akierman A, Alshaikh B, Yusuf K. Assessment of initial vancomycin dosing in neonates. Paediatr Child Health. (2014) 19:e30-34.

25. Pottel H, Vrydags N, Mahieu B, Vandewynckele E, Croes K, Martens F. Establishing age/sex related serum creatinine reference intervals from hospital laboratory data based on different statistical methods. Clin Chim Acta. (2008) 396:49-55. doi: 10.1016/j.cca.2008.06.017

26. Pawlotsky F, Thomas A, Kergueris MF, Debillon T, Roze JC. Constant rate infusion of vancomycin in premature neonates: a new dosage schedule. $\mathrm{Br} J$ Clin Pharmacol. (1998) 46:163-7.

27. Plan O, Cambonie G, Barbotte E, Meyer P, Devine C, Milesi C, et al. Continuous-infusion vancomycin therapy for preterm neonates with 
suspected or documented Gram-positive infections: a new dosage schedule. Arch Dis Child Fetal Neonatal Ed. (2008) 93:F418-21. doi: 10.1136/adc.2007.128280

28. Janssen EJH, Välitalo PAJ, Allegaert K, de Cock RFW, Simons SHP, Sherwin CMT, et al. Towards rational dosing algorithms for vancomycin in neonates and infants based on population pharmacokinetic modeling. Antimicrob Agents Chemother. (2016) 60:1013-21. doi: 10.1128/AAC.01968-15

29. Leroux S, Jacqz-Aigrain E, Biran V, Lopez E, Madeleneau D, Wallon C, et al. Clinical utility and safety of a model-based patient-tailored dose of vancomycin in neonates. Antimicrob Agents Chemother. (2016) 60:2039-42. doi: 10.1128/AAC.02214-15

30. Zhao W, Kaguelidou F, Biran V, Zhang D, Allegaert K, Capparelli EV, et al. External evaluation of population pharmacokinetic models of vancomycin in neonates: transferability of published vancomycin population pharmacokinetic models in neonates. Br J Clin Pharmacol. (2013) 75:1068-80. doi: 10.1111/j.1365-2125.2012.04406.x

31. Qiao Y, Ning X, Chen Q, Zhao R, Song W, Zheng Y, et al. Clinical and molecular characteristics of invasive community-acquired Staphylococcus aureus infections in Chinese children. BMC Infect Dis. (2014) 14:582. doi: 10.1186/s12879-014-0582-4

32. Healy CM. Features of invasive staphylococcal disease in neonates. Pediatrics. (2004) 114:953-61. doi: 10.1542/peds.2004-0043

33. Padari H, Oselin K, Tasa T, Metsvaht T, Lõivukene K, Lutsar I. Coagulase negative Staphylococcal sepsis in neonates: do we need to adapt vancomycin dose or target? BMC Pediatr. (2016) 16:206. doi: 10.1186/s12887-0160753-0

34. Lodise TP, Patel N, Lomaestro BM, Rodvold KA, Drusano GL. Relationship between initial vancomycin concentration-time profile and nephrotoxicity among hospitalized patients. Clin Infect Dis. (2009) 49:507-14 doi: $10.1086 / 600884$

35. Ingram PR, Lye DC, Tambyah PA, Goh WP, Tam VH, Fisher DA. Risk factors for nephrotoxicity associated with continuous vancomycin infusion in outpatient parenteral antibiotic therapy. J Antimicrob Chemother. (2008) 62:168-71. doi: 10.1093/jac/dkn080

36. Le J, Bradley JS, Murray W, Romanowski GL, Tran TT, Nguyen $\mathrm{N}$, et al. Improved vancomycin dosing in children using area under the curve exposure. Pediatr Infect Dis J. (2013) 32:e155-63. doi: 10.1097/INF.0b013e318286378e

37. Neely MN, Youn G, Jones B, Jelliffe RW, Drusano GL, Rodvold KA, et al. Are vancomycin trough concentrations adequate for optimal dosing? Antimicrob Agents Chemother. (2014) 58:309-16. doi: 10.1128/AAC.01653-13

38. Lestner JM, Hill LF, Heath PT, Sharland M. Vancomycin toxicity in neonates: a review of the evidence. Curr Opin Infect Dis. (2016) 29:237-47. doi: 10.1097/QCO.0000000000000263

Conflict of Interest Statement: The authors declare that the research was conducted in the absence of any commercial or financial relationships that could be construed as a potential conflict of interest.

Copyright (c) 2019 Tauzin, Cohen, Durrmeyer, Dassieu, Barre and Caeymaex. This is an open-access article distributed under the terms of the Creative Commons Attribution License (CC BY). The use, distribution or reproduction in other forums is permitted, provided the original author(s) and the copyright owner(s) are credited and that the original publication in this journal is cited, in accordance with accepted academic practice. No use, distribution or reproduction is permitted which does not comply with these terms. 